\title{
Self Learning Intelligent Controller of Electro hydraulic Actuator
}

\author{
Ayman A.Aly ${ }^{\mathrm{a}}$, Abdallah A. Alshennawy ${ }^{\mathrm{b}}$ A.Abo-Ismail ${ }^{\mathrm{c}}$, and S.Dossokey ${ }^{\mathrm{d}}$ \\ ${ }^{a}$ Mechanical Engineering Dept., Colleage of Engineering, Taif University, El-Hawiea, Taif,888, Saudi Arbia, \\ ${ }^{b}$ Design and prod. Eng. Dept. , Faculty of Engineering, Tanta University, Egypt \\ ${ }^{c}$ Mechanical Engineering Dept.,Faculty of Engineering, Assiut University,Assiut, 71516, Egypt, \\ ${ }^{d}$ Aeronautical and Aerospace Engineering Dept., Faculty of Engineering, Cairo University, Cairo, Egypt.
}

\begin{abstract}
The use of electro-hydraulic cylinders in industry has been becoming increasingly popular. A Fuzzy Logic Controller (FLC), which consists of the linguistic defined fuzzy sets and the control rules, is designed to control of the electro-hydraulic cylinder. Using the triangle shaped membership function; the position of the servo cylinder was successfully controlled. When the system working condition is altered, the control algorithm is shown to be more robust compared to the PID controller.
\end{abstract}

Index Terms: Intelligent Position Control, Fuzzy Logic Control, PID, Electro hydraulic.

(C) 2013 Published by MECS Publisher. Selection and/or peer review under responsibility of the Research Association of Modern Education and Computer Science.

\section{Introduction}

Electro hydraulic servodrives are widely used in versatile industrial applications such as machine tools, industrial robots, autonomous manufacturing systems and various actuators in aircraft. They can be applied in closed-loop control systems to achieve accurate force, velocity or position control [1].

In industrial applications, the dynamic characteristics of the servo-hydraulic system are always complex and highly nonlinear. Moreover, there are too many uncertainties in it; for example, the viscosity of oil, the bulk modulus, the oil volume, the system pressure, the wear and the cavitations [2]. The loading conditions are usually rather unsteady, and the loading forces change in a wide range during operation.

When the process is complex and nonlinear with variable parameters, the conventional control theory can not be applied. The modern control theory and adaptive control techniques have been used to control that plant. However, the adaptive control requires accurate mathematical control model or lot of computational effort to estimate and adapt the controller parameters [3]

Hydraulic cylinder system is a nonlinear one with variable parameters. It is difficult to meet control

* Corresponding author. Tel.:

E-mail address: ${ }^{\text {d draymanelnaggar@yahoo.com }}$ 
demands or obtain satisfactory performance by adopting traditional PID tuning techniques. An alternative approach to control the complex plant is to investigate the control strategy employed by the human operator. The non-mathematical approach called "Fuzzy Set Theory" [4], [5] is suitable for developing reliable logic controller for plants with wide parameters variations. In this paper, an intelligent Fuzzy controller (IFC) is presented for position control of an electro hydraulic servo.

\section{Mathematical model and specifications of the system}

The main reasons to use positioning servos in industry are the demands on the accuracy, the stiffness and good dynamic responses to the changes in the command signal or the load.

\subsection{The Electro hydraulic Servo Valve Transfer Function}

From Moog Technical bulletin, a convenient form for the servo valve transfer function, [2] is:

$$
\frac{Q_{v}(s)}{I(s)}=\frac{C_{v}}{\left(1+\tau_{v} s\right)\left(\frac{s^{2}}{\omega_{v}^{2}}+\frac{2 \zeta_{v}}{\omega_{v}} s+1\right)}
$$

where $Q_{\mathrm{v}}$ is the valve main stage flow rate, $I$ is the valve input, $C_{v}$ is the total valve flow gain, $\tau_{v}$ is the valve time constant and $\omega_{v}, \zeta_{v}$ are the undamped natural frequency and damping ratio of the valve respectively.

\subsection{Hydraulic Actuator Transfer Function}

The equations of the servovalve flow to and from the actuator (assuming symmetric valve port, zero lap design and zero return pressure) are as follows,

For $\mathrm{Xv} \geq 0$

$$
Q_{f}=C_{d} W X_{v} \operatorname{sgn}\left(P_{s}-P_{f}\right) \sqrt{\frac{2}{\rho}\left|P_{s}-P_{f}\right|}, Q_{n}=C_{d} W X_{v} \operatorname{sgn}\left(P_{n}\right) \sqrt{\frac{2}{\rho}\left|P_{n}\right|}
$$

For $\mathrm{Xv} \leq 0$

$$
Q_{f}=C_{d} W X_{v} \operatorname{sgn}\left(P_{f}\right) \sqrt{\frac{2}{\rho}\left|P_{f}\right|}, Q_{n}=C_{d} W X_{v} \operatorname{sgn}\left(P_{s}-P_{n}\right) \sqrt{\frac{2}{\rho}\left|P_{s}-P_{n}\right|}
$$

where $X_{v}$ is the spool displacement, $P_{s}$ is the supply pressure, $\rho$ is the mass density of the oil, $C_{d}$ is the discharge coefficient of the orifice, $W$ is the width of the orifice, suffix $n$ denotes the annular side and suffix $f$ denotes the full side.

The linearized flow equation of the actuator is given by [6]: 
$q_{l e}=K_{l} \frac{A_{e}}{A_{f}}\left[\frac{1+\left(\frac{A_{n}}{A_{f}}\right)^{2}}{1+\left(\frac{A_{n}}{A_{f}}\right)^{3}}\right] p_{l e}+A_{e} \dot{X}_{p}+\frac{2 A_{e}}{A_{f}} \frac{\dot{P}_{l e}}{4 B}\left[\frac{V_{f}+\left(\frac{A_{n}}{A_{f}}\right)^{2} V_{n}}{1+\left(\frac{A_{n}}{A_{f}}\right)^{3}}\right]$

where $P_{l e}=\frac{p_{f} A_{f}-p_{n} A_{n}}{A_{e}}, \quad q_{l e}=\frac{q_{f}+q_{n}}{2}, A_{e}=\frac{A_{f}+A_{n}}{2}$,

Ple is the effective load pressure, qle is the effective load flow rate, Ae is the effective piston area, B is the oil bulk modulus, $\mathrm{k} 1$ is the leakage coefficient of the piston, $\mathrm{Xp}$ is the piston displacement, $\mathrm{Vn}$ is the oil volume under compression in the annular side of the cylinder, $\mathrm{Vf}$ is the oil volume under compression in the full side of the cylinder, An is the annular area of the cylinder, Af is the full area of the cylinder.

It is assumed that the loading point may be treated as a mass-damper system. The linearized equation for the force developed by the actuator on the loading point, after eliminating the steady state terms, can be written as

$f_{a}=M \ddot{X}_{p}+B_{l} \dot{X}_{p}$

where $M$ is the mass of the load concentrated at the loading point and $B_{l}$ is the viscous damping coefficient of the structure at that loading point.

Equations (2), (3), (4) and (5) may be manipulated and Laplace transformed to give the actuator displacement:

$$
X_{p}(s)=\frac{\frac{K_{v}}{A_{e}} X_{v}(s)}{\frac{M V_{t}}{4 B A_{e}{ }^{2}} s^{3}+\left(\frac{K_{c} M}{A_{e}{ }^{2}}+\frac{B_{p} V_{t}}{4 B A_{e}{ }^{2}}\right) s^{2}+\left(1+\frac{K_{c} B_{p}}{A_{e}{ }^{2}}+\frac{K_{s} V_{t}}{4 B A_{e}{ }^{2}}\right) s}, V_{t}=\frac{2 A_{e}}{A_{f}}\left[\frac{V_{f}+\left(\frac{A_{n}}{A_{f}}\right)^{2} V_{n}}{1+\left(\frac{A_{n}}{A_{f}}\right)^{3}}\right]
$$

where $B_{p}=B_{1}+K_{v f}, K_{v f}$ is the viscous friction coefficient of the piston, $K v$ is the flow/displacement gain for the main stage of the valve, $K_{c}$ is the total flow-pressure coefficient and $V_{t}$ is the effective trapped oil volume. It can be presented in standard form so as to reveal equivalent values of natural frequency and damping ratio may be written for the asymmetric actuators as

$$
\omega_{\mathrm{O}}=\sqrt{\frac{4 B A_{e}^{2}}{V_{t} M}} \text { and } \delta=\frac{K_{c}}{A_{e}} \sqrt{\frac{B M}{V_{t e}}}+\frac{B_{p}}{4 A_{e}} \sqrt{\frac{V_{t}}{B M}}
$$


$X_{p}(s)=\frac{\frac{K_{v}}{A_{f}} X_{v}}{s\left(\frac{s^{2}}{\omega_{0}^{2}}+\frac{2 \delta}{\omega_{0}} s+1\right)}$

where $X_{p}$ is the piston position, $\delta$ is the load damping ratio and $\omega$ o is the load natural frequency.

\subsection{Closed Loop Transfer Function for The System}

In this section the closed loop transfer function for the single-rod actuator system operating on the load is developed.

The equations may be manipulated to obtain the closed-loop transfer function relating the error voltage $\mathrm{Ve}(\mathrm{s})$ and the output voltage $\mathrm{VO}(\mathrm{s})$ representing the position signal. The specifications of the system are indicated in Table 1 and Fig. 1 and the block diagram is shown in Fig. 2.

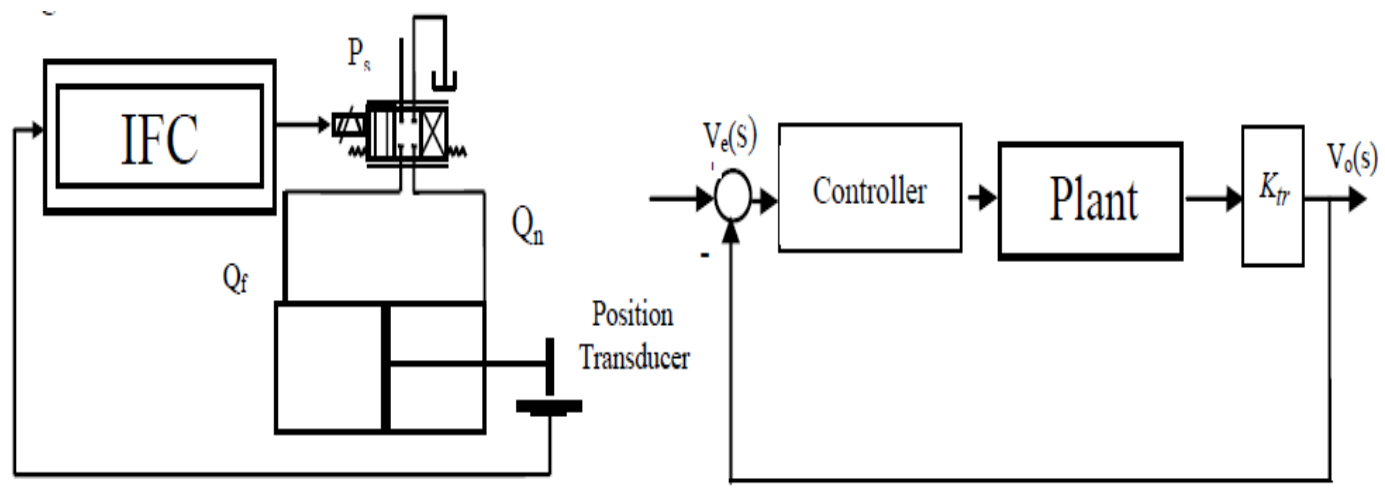

Fig.1 Schematic diagram of the cylinder

Fig.2 Block diagram representation of single-actuator system

The transfer function for the single-actuator system is

$$
\frac{V_{o}(s)}{V_{e}(s)}=\frac{K_{o}}{\left(\tau_{v} s+1\right)\left(\frac{s^{2}}{\omega_{v}^{2}}+\frac{2 \zeta_{v}}{\omega_{v}} s+1\right) s\left(\frac{s^{2}}{\omega_{o}^{2}}+\frac{2 \delta}{\omega_{o}} s+1\right)}
$$

where $K_{o}=\frac{K_{t r} \cdot C_{v} \cdot A_{f}}{K_{v}}, V_{o}$ is the output voltage according to the piston position, $V_{e}$ is the error signal voltage, $K_{o}$ is the overall system gain and $K_{\mathrm{tr}}$ is the position transducer gain. 
Table 1 Specifications of the system

Diameter of piston

Diameter of piston rod

Stroke

Load natural frequency

Load damping ratio

Total flow pressure coefficient

Valve flow gain, no load

Natural frequency of servo valve

Damping factor of servo valve

Supply pressure

House - delay time

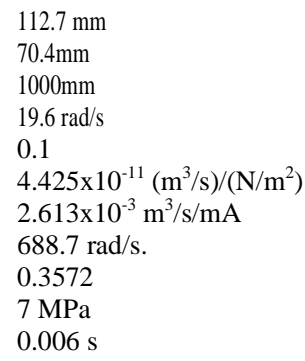

$7 \mathrm{MPa}$

$0.006 \mathrm{~s}$

\section{Fuzzy logic controller}

\subsection{Knowledge Base}

The knowledge base consists of a data base and a rule base. The data base provides information for the proper operation of fuzzyfication, inference, and defuzzyfication. This information consists of the input and the output membership functions and other information vital to the process. The rule base is a collection of linguistic statements relating the input signals to the desired outputs.

\subsection{Fuzzification}

The process of fuzzification receives a crisp input signal, normalise it and classifies it into membership functions. Each membership function, is assigned to the signal and identified by a linguistic variable: light, small, large and very large. The shapes of the membership functions are typically triangular or exponential. In this paper triangular membership functions are used. Fig. 3 shows triangular membership functions, for the error and change in error, with fuzzy labels NP (negative big), NM(negative medium), NS(negative small), ZO (zero), PS(positive small), PM(positive medium) and PB (positive big).

In the case of the triangular function shown in Fig. 3(a), the normalized error signal has membership in the ZO and PS functions, while Figure 3(b) shows the change in error signal with membership in the NS and ZO functions. The values of points $a$ and $b$ represent the grade of membership of the error in the ZO and PS functions, and the values of points $c$ and $d$ represent the grade of member ship of the change in error in the NS and $\mathrm{ZO}$ functions. The sum of $\mathrm{a}$ and $\mathrm{b}$, and the sum of $\mathrm{c}$ and $\mathrm{d}$, will always be equal to one for triangular membership functions.

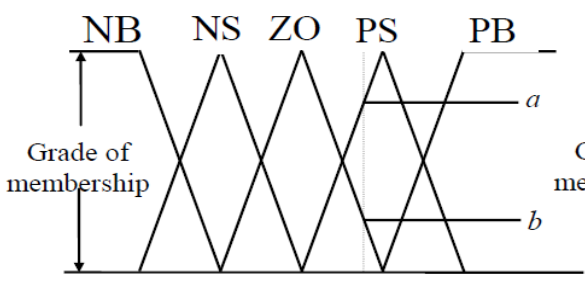

(a) Error

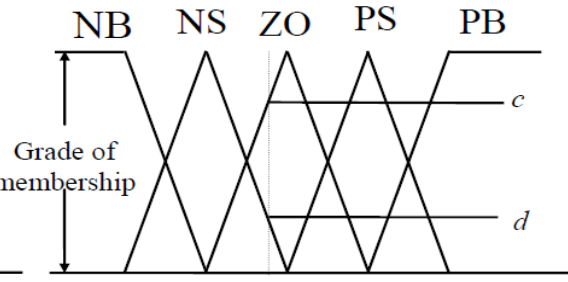

(b) Change in error

Fig.3 Triangular membership function 


\subsection{The Inference Process}

The basic operation of the inference process is to determine the values of the of the controller output based on the contributions of each rule in the rule base. One method of storing the rule base is the use of the Macvicar - Whelan control matrix [4] (Table 2). This matrix is designed so that if the desired output is realized with zero change in error, then the output remains constant. However, if the output is different from the desired response, then the rules produce an output signal based on human knowledge of the operating system. Each element of the matrix describes a rule of the form:

If $e(t)$ is $E i$ and $\operatorname{de}(t)$ is $d E j$ then $f(t)$ is $C i, j$,

where $e(t)$ and $d e(t)$ are the error and change in error, $f(t)$ is the controller output, Ei and $\mathrm{dEj}$ are the applicable input function, and $\mathrm{Cij}$ is the output function.

Table 2 Macvicar - Whelan fuzzy rule matrix.

\begin{tabular}{|c|c|c|c|c|c|}
\hline \multicolumn{6}{|c|}{$e(t)$} \\
\hline & NB & NS & $\mathrm{ZO}$ & PS & PB \\
\hline $\mathrm{NB}$ & $\mathrm{NB}$ & NB & NB & NS & $\mathrm{ZO}$ \\
\hline NS & $\mathrm{NB}$ & $\mathrm{NB}$ & NS & $\mathrm{ZO}$ & PS \\
\hline $\mathrm{ZO}$ & $\mathrm{NB}$ & NS & $\mathrm{ZO}$ & PS & $\mathrm{PB}$ \\
\hline PS & NS & $\mathrm{ZO}$ & PS & $\mathrm{PB}$ & PB \\
\hline $\mathrm{PB}$ & $\mathrm{ZO}$ & PS & PB & PB & PB \\
\hline
\end{tabular}

\subsection{Defuzzification}

Choosing triangular membership functions, for the input signals, ensures that a max. of four rules apply for the error shown in Fig. 3(a) and the change in error shown in Fig. 3(b). To determine the output values, a weighted average of the active rules is used as follow:

$F(t)=\frac{a \cdot c \cdot P S+a \cdot d \cdot Z O+b \cdot c \cdot Z O+b \cdot d \cdot N S}{a \cdot c+a \cdot d+b \cdot c+b \cdot d}$

$\mathrm{F}(\mathrm{t})$ is the controller output, a and $\mathrm{b}$ represent the membership values for the error, $\mathrm{c}$ and $\mathrm{d}$ represent the membership values for the change in error, and the terms NS,ZO,PS are the peak values of the output membership functions. It should be noted that the denominator in (9) will be one when the triangular function are symmetric.

\subsection{Fuzzy Controller Design Procedure}

The block diagram of the structure of fuzzy control system is shown in the Fig. 4. The fuzzy logic controller designed include three important steps: Fuzzification, fuzzy reasoning and defuzzification. The error and the change in error will be fuzzified with the membership function. The used membership functions of error and change in error are triangles shaped, which is shown in Fig. 3.

The design procedure of the fuzzy controller is as follows:

- Choice of the state variables and the membership functions for the fine regulation, the larger the number of the fuzzy state valuables the more control rules will be. But the control rules will be more complex and difficult to design. To reduce the number of the control rules and to achieve good control performance are important for the fuzzy controller design. 
- Determine the control rules as described in Table 2.

- Defuzzify the control signal through the defuzzification process to determine the control signal U.

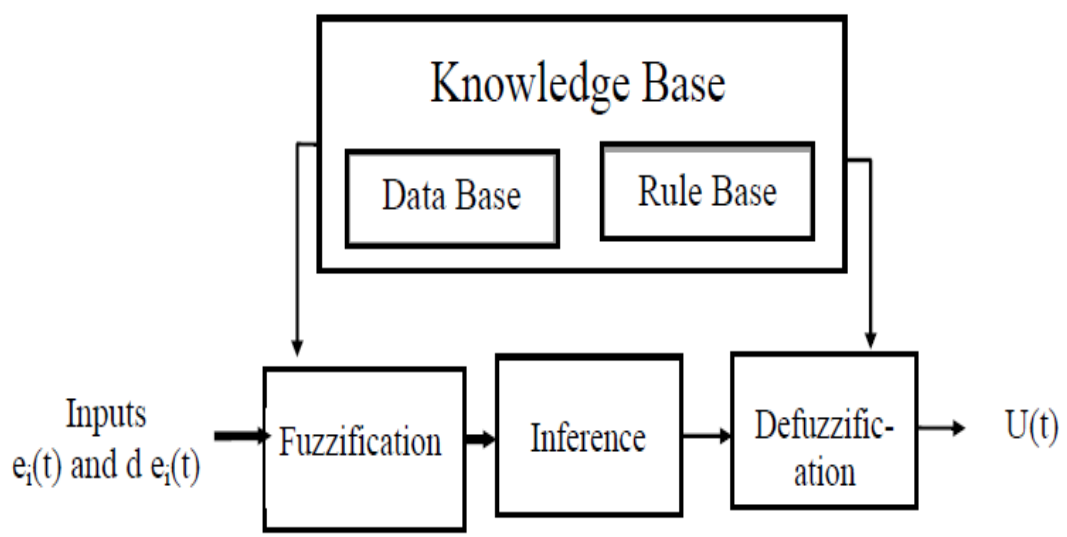

Fig.4 Fuzzy logic controller

\section{Simulation results}

The simulation results to step response are shown in Figures 5 and 6 with PID and FLC are simulated under the same loading conditions. By comparing these two figures beside Fig. 7, it can be observed that the IFC has an excellent control performance than traditional PID, and it removes over shoots and oscillation.

Figures 8-9 show that the PID control is sensitive to the plant parameters variations (load damping ratio and frequency). In the other hand the FLC is insensitive to the parameter changing of the plant. Figures 10-11 show another advantage of FLC compared with PID control with positive step disturbance rejection. It is more faster and without oscillations. In Fig. 12 the response of the system under FLC policy offered robust response even with characterized by different delay times.

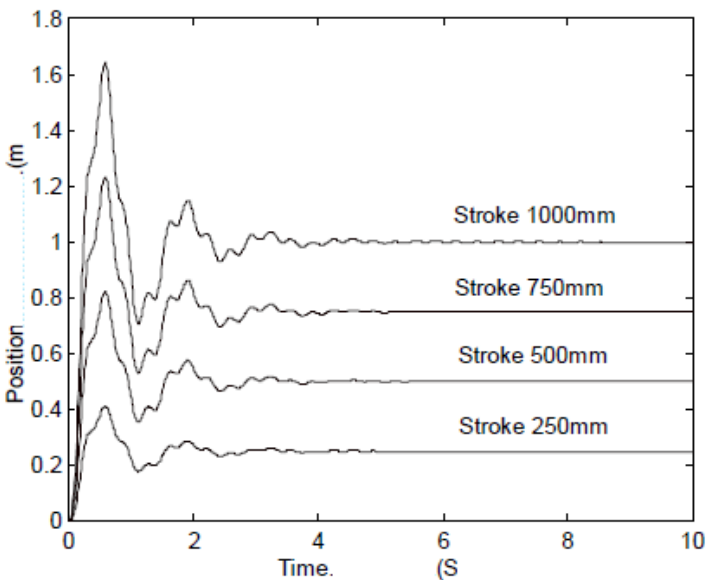

Fig. 5 System Step Response Based on PID Controller

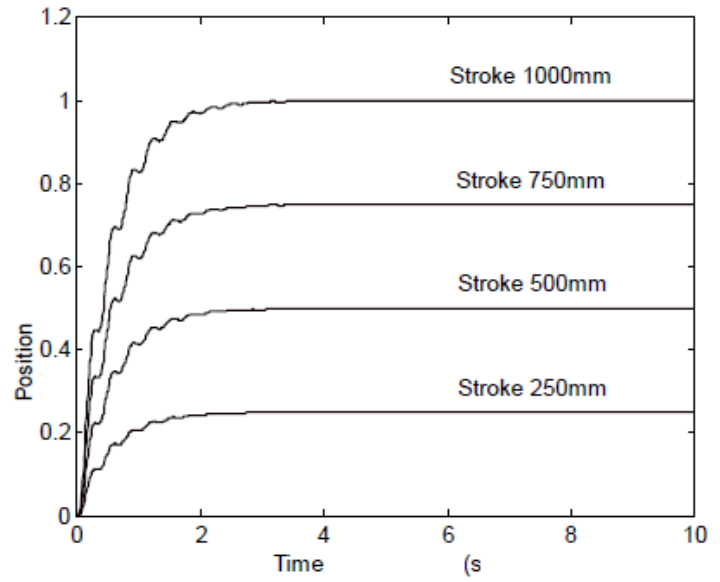

Fig. 6 System Step Response Based on Fuzzy Logic Controller 


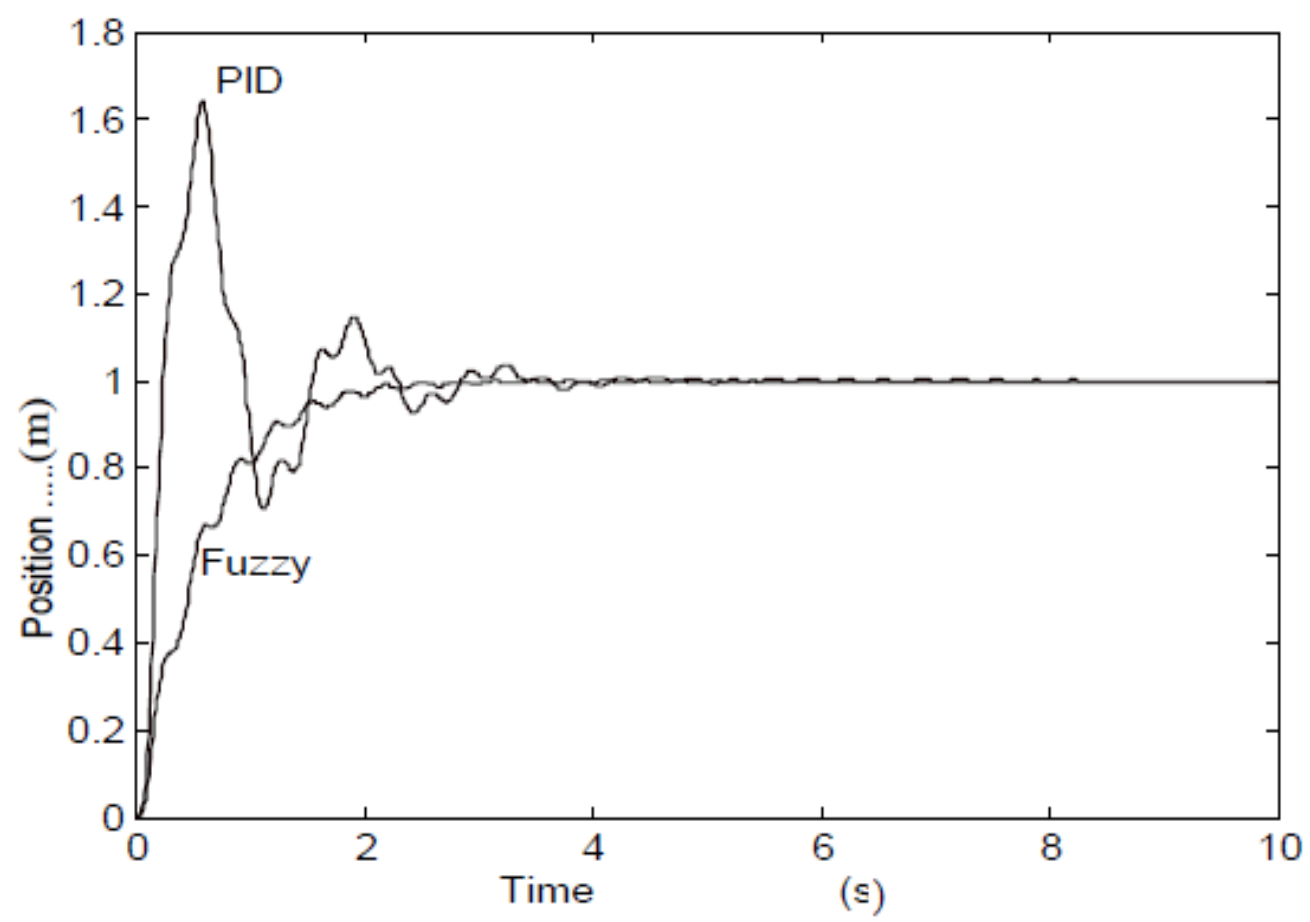

Fig. 7 System step response based on PID and Fuzzy Logic Controllers
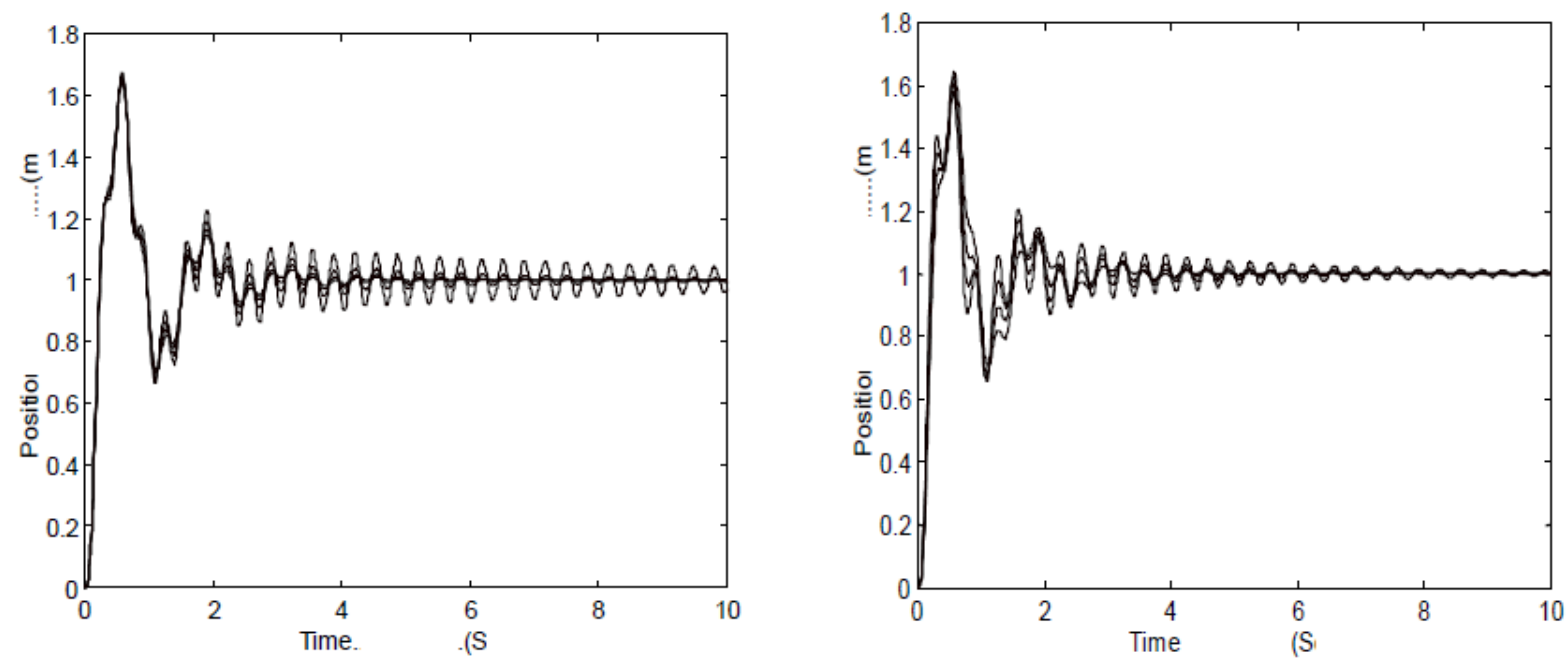

Fig. 8 System step response based on PID controller with $\omega 0$ variations
Fig. 9 System step response based on PID controller with $\delta$ variations 


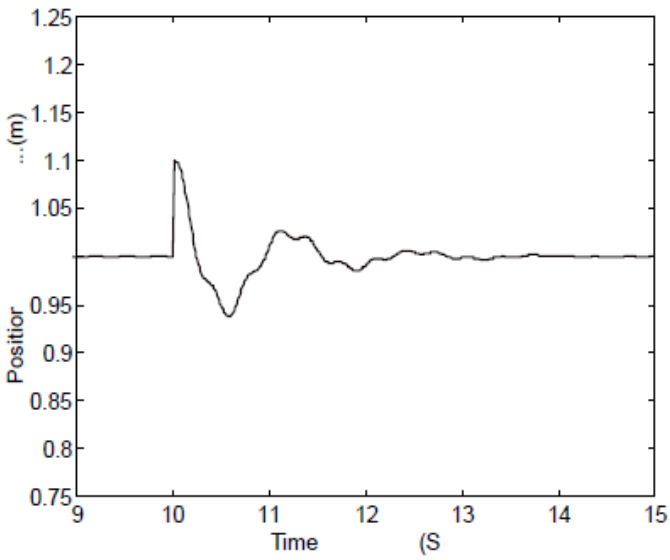

Fig. 10 System positive step disturbance response basd on PID controller

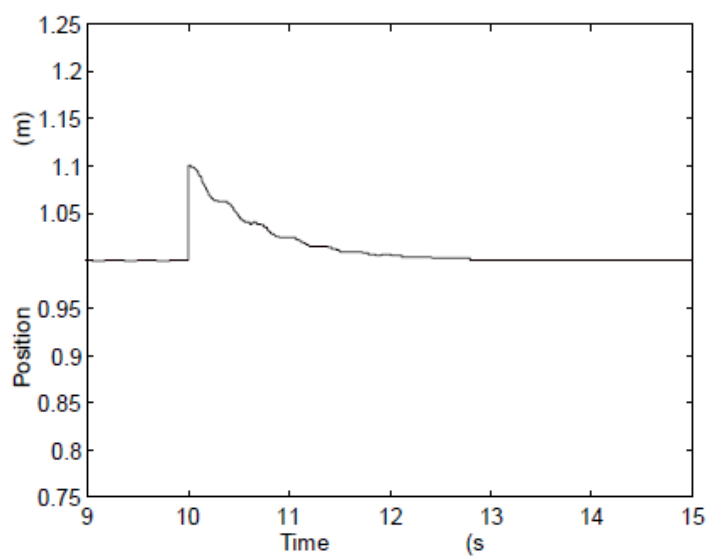

Fig. 11 System positive step disturbance response basd on Fuzzy logic Controller

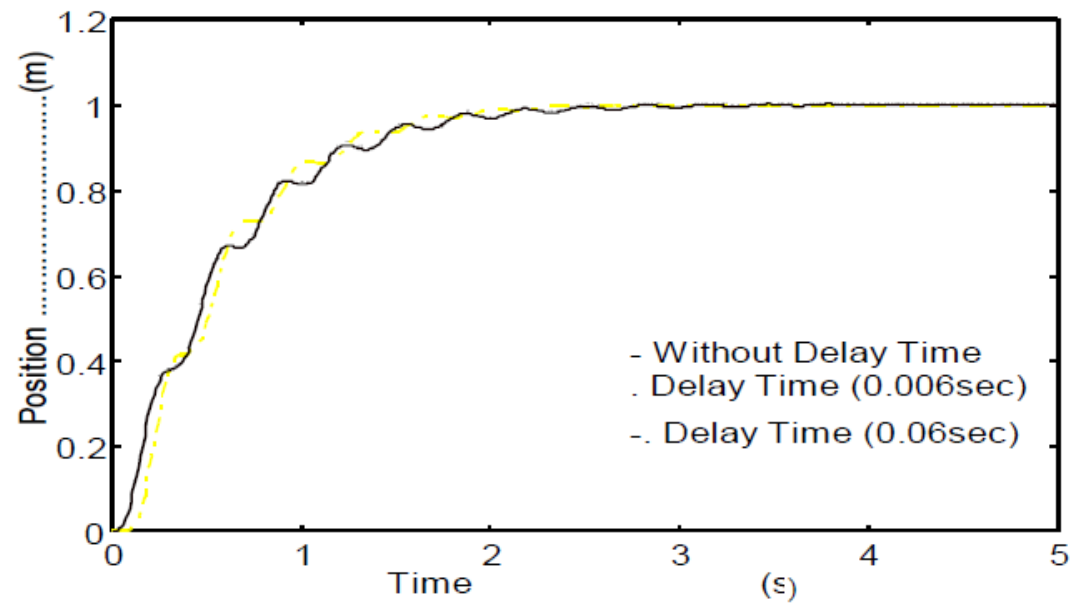

Fig. 12 System step response with and without delay time base on Fuzzy Logic Controller

\section{Conclusion}

The control problem of electro-hydraulic cylinder is studied in this paper. A self learning intelligent controller based on fuzzy logic and control knowledge has been given. It is shown that the intelligent fuzzy controller has a good learning effect and robust control performance.

The main advantage of the FLC:

- The control algorithm is simple and does not need a precise model.

- When the system working condition is altered, i.e., the damping ratio or the frequency is changed, the control algorithm is much more robust than that of the PID.

- The algorithm is easy to implement even on small microprocessor systems. The successful application of the FLC on the hydraulic power system is a breakthrough in this field. Extending this proposed FLC policy for MIMO servo systems is a very important and promising application. 


\section{References}

[1] Ayman A. Aly, "Model Reference PID Control of an Electro-hydraulic Drive" I. J. Intelligent Systems and Applications (IJISA), 11, 24-32, 2012.

[2] Ayman A. Aly, "Intelligent fuzzy controller with road surfaces identifier for antilock brake system," Int. J. Mechatronics and Automation (IJMA), Vol. 1, Nos. 3/4, pp 153-160, 2011.

[3] Zhao,T. and Virvalo,T., "Fuzzy State Controller and Its Application in Hydraulic Position Servo", Fluid power, Page 417, (1993).

[4] Zhang, B., and Edmunds, J., "Self - Organizing Fuzzy Logic Controller", IEEE Vol. 139, No.5 Sept. (1992).

[5] Ali Yousef and Ayman A. Aly, "Effect of Non-linearities in Fuzzy Approach for Control A Two -Area Interconnected Power System", IEEE International Conference on Mechatronics and Automation (ICMA 2010) China, August 4-7, 2010.

[6] Purows, L., Ch.4,"Control of Fluid Power Analysis and Design", Van Nostrand Reinhold Company, New York, (1987)

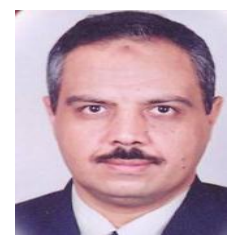

Associate Prof. Dr. Ayman A. Aly is the head of Mechatronics Section at Taif University, Saudi Arabia since 2008. Prior to joining Taif University, He is also one of the team who established the "Mechatronics and Robotics Engineering" Educational Program in Assiut University in 2006. He was in the Managing and implementation team of the Project "Development of Mechatronics Courses for Undergraduate Program" DMCUP ProjectHEEPF Grant A-085-10 Ministry of Higher Education - Egypt, 2004-2006.

The international biographical center in Cambridge, England nominated and selected Ayman A. Aly as the International Educator of the year 2012. Also, Ayman A. Aly nominated and selected for inclusion in Marquis Who's Who in the World, 30 ${ }^{\text {th }}$ Pearl Anniversary Edition, 2013.

In additions to 5 text books, Ayman A. Aly is the author of more than 60 scientific papers in Refereed Journals and International Conferences. He supervised some of MSc. and PhD. Degree Students. His main areas of research are Robust and Intelligent Control of Mechatronics systems, Automotive control systems, Thermofluid systems modeling and simulation.

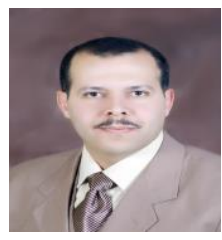

Dr. AbdallAh A. Alshennawy was Born in El Mansoura -Egypt, at 1968-03-10, B.Sc. 1991 and M.Sc. in Computer Vision of Two Dimensional Measurement and Inspection from Prod. And Design Eng. Dept., El Mansoura University, Egypt, 1995 and PhD. in Computer Vision of Three Dimensional Measurement and Inspection from Prod. And Design Eng. Dept., El Mansoura University, Egypt, 2003. Nowadays, he is a Lecturer at the Production and Design Engineering dept., Faculty of Engineering, Tanta University, Egypt.

How to cite this paper: Ayman A.Aly,Abdallah A. Alshennawy,A.Abo-Ismail,S.Dossokey,"Self Learning Intelligent Controller of Electro hydraulic Actuator", IJEM, vol.3, no.1, pp.28-37, 2013.DOI: 10.5815/ijem.2013.01.03 